\title{
Expansion of International Exchanges and Cooperation, Strengthen Marine Application and Development
}

\author{
Qing $\mathrm{Cao}^{1, \mathrm{a}}$ \\ ${ }^{1}$ Research Department, \\ Tianjin Maritime College, \\ Tianjin, China \\ a1035489485@qq.com
}

\author{
Ranran Wang,b \\ ${ }^{2}$ English Teaching Department, \\ Tianjin Maritime College, \\ Tianjin, China \\ bxym4800658@163.com
}

\author{
Yanming $\mathrm{Xu}^{3, \mathrm{c}}$ \\ ${ }^{3}$ Maritime Engineering Department, \\ Tianjin Maritime College, \\ Tianjin, China \\ cwrrtianjin@163.com
}

\begin{abstract}
With the implementation of Chinese maritime powers strategy, it is more and more important and urgent to friendly communicate with the traditional marine countries. The government, enterprises, and non-government organizations need to work together to strengthen the cooperation in important areas of law, economy, scientific research, education, tourism, etc.
\end{abstract}

Keywords-marine strategy; cooperation; communication; maritime silk road.

\section{INTRODUCTION}

The 21st century is an ocean century. China is both a land power and also the sea superpower. In order to realize the revival of Chinese Nation, China actively implements the sea power strategy to construct "Marine Silk Road of Twenty-first Century". While improving the blue power, international communication and cooperation are also needed. On June 20th, 2014, Premier Li Keqiang attended Marine cooperation BBS in Athens with Greece prime Samaras, 2015 was classified as bilateral ocean cooperation year. On July 24th, 2014, when in Portugal for transit stops by special plane, President Xi Jinping put forward strengthening pragmatic cooperation in ocean areas to promote bilateral relations to a new level. On August 27th and 28th, 2014, China host the 4th Marine Ministers' Asia-Pacific Economic Co-operation (APEC) for the first time. Mutual benefit and actively promoting international cooperation in marine field become the conference theme. In regard to the development of marine application, China is actively seeking international exchanges and cooperation and seeking common development.

\section{IMPORTANT FIELDS}

\section{A. Marine Laws}

The country rejuvenating history of most western developed countries is closely linked to marine development, which has formed a set of relatively complete domestic and international marine law system, and plays an important part in the international marine problems for a long time. Japan, Vietnam, Philippine, Malaysia and other neighbor countries only gives a general classification of the continental shelf and the exclusive economic zone by the United Nations Convention on the Law of the Sea, failed to fully take care of the historic marine rights of relevant countries. They just adopt various ways to occupy, claim for the traditional Chinese waters, trying to a fait accompli to force China to make concessions. China's real security situation urgently needs to maintain and explain the authority of international law. At the same time, the booming of China programs also needs the guarantee of legal systems.

\section{B. Ocean Industry}

Marine economy is the foundation of marine power construction. China gross ocean production in 2013 is about $\$ 5.4$ trillion, accounting for $9.5 \%$ of the gross domestic product (GDP). Marine fishery, marine transport, marine shipbuilding industry, marine oil-gas industry, salt industry, coastal tourism industry belong to the traditional marine industries, in the dominant position; the ocean emerging industries such as seawater desalination industry, marine biological pharmaceutical, marine engineering construction, and marine electricity are on the rise, show a strong vitality. Although China marine industry develops fast, it is still very backward compared with the developed countries. The structure and layout are not reasonable, and the overall marine industry level is 10 years behind the developed countries. The Chinese and foreign marine trade 
is still at the most basic level, there is a considerable distance to go to achieve the level of the European Union and north American free trade area. In the future, it needs to rely on mutual trust and macro policy, to promote direct investment and currency, constantly raising the level of opening in free trade zone.

\section{Marine science and Technology}

The battle over the ocean between countries is in fact science and technology. In 1997, the world Ocean Commission divided the issues of the current development of the marine science and technology into four categories: (1) the progress of science and culture, including researches revealing the origin of life, the universe origin and human origin (ocean) anthropology; (2) the exploration and development of marine wealth, including biological resources development (mainly fisheries), oil and gas resources development, marine transportation, energy, space utilization and tourism, the marine environment purification capacity; (3) research and protection of life support systems, including ocean and climate, biodiversity, health, and waste removal, disaster prevention and mitigation, etc; (4) other classes, including marine management, marine science and economics, logics, coast, training and education. Many of the marine science and technology major projects, such as the worldwide "big ocean science” (observation system, deepwater drilling, ecosystem, off coast science, biological diversity), requiring multi-national and regional cooperation. In these areas, China has certain ability to research, especially attaches great importance to the fields of marine economy, marine biology, marine environmental protection, marine mineral and water use, which also have close relationship with Chinese actual interests. As a coastal power, China must participate in international competition and cooperation in the field of ocean, and to strengthen learning in some vulnerable areas such as marine archaeology.

\section{Training for Seafarers}

Up to December 31st, 2013, the number of registered seamen of China is 574,117 , double of 2009 , is No.1 of the world; the number of seafarer overseas assignment is 119316, which is second of the world. There are total 80 navigation colleges in China, 217 officer service agencies, and 200 seafarer overseas assignment agencies.

At present, the global shortage of seafarers and structural contradictions are increasingly expanding, and the STCW convention implementation work is recognized by the maritime safety administration and other relevant European Union countries, which will further enhance the comparative advantage of sailors from output countries like China and Philippine in the international seamen in market competition, created an important period of strategic opportunities for Chinese seafarers to go out.

Meanwhile, the quality of Chinese seafarers is not dominant. Main reasons are: (1) the English level is a key restricting factor;(2) subjective consciousness, working attitude and team work spirit quality still need to promote;(3) cultural differences, lead to life and communication ability not strong;(4) the lack of senior seamen, and there is a gap with foreign ship management level. To improve the competitiveness of the Chinese seafarers, we must promote in education and training, more communications and in line with the advanced international practices step by step.

\section{E. Marine Tourism}

Marine tourism is gradually becoming a hot spot of tourism, becoming people's psychological needs of relax and recreation, and embrace of the nature. Many marine tourism destinations abroad have been highly developed. With the advantages of diverse product selection: high, medium and low-end product structure, complete, perfect green environment planning, irreplaceability, etc.

Some of the world mature development experience of marine tourism is worth using for reference. China marine tourism is in active construction of tourism development. The domestic cruise yacht tourism increases just now. In 2013, the national tourism administration will be the annual travel, slogan "2013 China's ocean tourism year" for the "experience ocean, tour of China", slogans are: "ocean tourism, lead the future", “ocean tourism, brilliant”. Through to the marine tourism resources development, make fist marine tourism products, rich Chinese tourism products, improve international appeal.

\section{F. Navy Power}

Adhering to the reconciliation of development strategy and military deterrence and oceanography is the fine tradition of Zheng he fleet to China. To held high-level close naval joint visits, Chinese and foreign students visit meetings, joint protecting sea lanes, and to practice "mutual trust, mutual benefit, equality and cooperation" as the core of "new security concept".

\section{ADHERENCE TO THE FOLLOWING PRINCIPLES}

\section{A. Ocean Sovereignty Interests}

At the end of the 19th century, an American called Alfred Thayer Mahan put forward "sea power theory", which reveals the close relationship between the national rise and fall and the ocean, and also the theory of marine trade and prosperity of countries, which had a great influence in the after world history. Even in the globalization at present, its rationality has still not disappeared. Nowadays, all countries are seeking ways to strengthen its maritime rights and interests, to ensure the security of the ocean. Actually, China's modern history is also a process of ocean sovereignty interest policy changes and historical adjustment. In dealing with all kinds of complicated situations of foreign countries, China improves the ability of marine rights, resolutely safeguard maritime rights and interests.

\section{B. Cultural Exchange Consensus of Maritime Silk Route}

History is a precious treasure of China. Maritime silk road culture in our country has a profound historical 
accumulation, especially in the current rising up marine development background, the construction of the marine silk road has important guiding significance to improve the level of opening to the outside world, and constructing new pattern of opening to the outside world. In October 2013, Xi Jinping, general secretary of China visiting ASEAN countries put forward the construction of maritime silk road in the 21st century. Then the third plenary session of the 18th Party meeting proposed to promote the silk road economic belt and maritime silk road construction, to form a new pattern of all-around opening up through the land and sea as a whole. And then prime Li Keqiang pointed grasping the planning and construction the 21st century maritime silk route in 2014 the government work report of the two sessions.

Currently, culture of mutual respect is the foundation of economic cooperation. Cultural exchange is more important than economic cooperation, and cultural exchange is the lubricant of the latter. In order to prompt "Marine silk road" of the 21st century ideas become the consensus of countries align as soon as possible, different culture should be inherited from the ancient maritime silk road in the spirit of mutual respect, cultural exchanges and cooperation for leading, enhance understanding and trust, create favorable humanistic development soft environment for the 21st century maritime silk route.

\section{Peace, Harmony and Cooperation}

China has both land and sea, its marine culture has its own characteristics. Compared to the western marine culture characteristics of daring attack and pioneering, Chinese ocean culture bears more heavy righteousness, harmonious, and tolerance, which is coherent with the Chinese ideas "No expansion, never seek for hegemony, peaceful development”.

\section{DEVELOPING METHODS}

\section{A. Government}

\section{1) Policy First}

"Special policy" is one of magic weapon to obtain the fruits of reform and opening-up along the coastal area of China. Since entering the "twelfth five-year", the coastal parts of the country pay more attention to the development of marine economy. The marine economy development of five coastal provinces and municipalities including Shandong, Zhejiang, Guangdong, Fujian and Tianjin directly turns into national strategy. Zhoushan islands, Pingtan comprehensive experimental zone and Hengqin peninsula was approved by the state council as national new district, which places can be used as the first model of Chinese and foreign marine cooperation in a new round of openness. Inland regions such as Sichuan and Guizhou can take "enclave" cooperation mode, also can’t fall behind in terms of policy.

2) Maritime Silk Road

After the successful application of joint cultural heritage "silk road on land" of China, KZ and Kyrghyzstan, China can continue to application for world cultural heritage "Marine silk road" with other countries. The main participants of China mainland are Nanjing and Yangzhou of Jiangsu province, Ningbo of Zhejiang province, Quanzhou, Fuzhou, Zhangzhou of Fujian province, Penglai of Shandong province, Guangzhou of Guangdong province, Beihai of Guangxi province, and Hainan province. Application for world cultural heritage is a long process. It's hard for a single point to succeed, which needs the national level to arrange, and to clarify the historical facts and the sovereignty of the South China Sea.

To further enhance maritime cooperation with ASEAN and related countries, actively implement the marine areas cooperation agreement, and add substantial contents together for the construction of the 21st century "Marine Silk Road”.

\section{3) Connecting and Cooperation between Friendly} Countries and Cities

Actively develop cooperation with developed ocean countries and cities in the fields of economy, trade, energy, finance, service, docking and infrastructure, etc. At present, China has established friendly relations with more than one thousand cities in the world. The increasingly frequent cultural activity, language education and training, tourism, economic development, official visit between sister cities effectively diminish the cultural barriers, and promote mutual understanding and communication between different countries.

4) To build an Exchange Platform

Through platforms like Hi-tech Expo and Xiamen International Ocean Week, to further strengthen science and technology cooperation with coastal countries, develop blue economy together to benefit the world.

\section{5) Scientific Research}

To cooperate with relevant countries in the field of ocean and polar scientific research; to earnestly implement the international obligations as marine disaster prevention and mitigation, marine ecological environment protection and so on, to strengthen specialized talents such as marine disaster prevention and mitigation to help relevant countries and regions.

\section{B. Enterprises}

Marine development needs the support of the real economy. Enterprises actively go out and utilize overseas ocean resources, to improve the international influence of Chinese marine brands.

\section{Colleges}

Navigation colleges should draw lessons from traditional maritime power development, such as Britain and America, the advanced experience of nautical education, from the top level design deepen maritime talent training mode reform, strengthen the teaching conditions from the infrastructure construction, strengthen sailing from practice enhance students' actual ability, from the campus cultural atmosphere cultivate excellent seamen's psychological and physical quality.

Promote academic exchanges and resource sharing between universities and research institutions both home 
and abroad, especially in the aspects of marine science and marine education.

Organization between teachers and students in ordinary comprehensive colleges and universities, to carry out Chinese and foreign marine camp, marine environmental protection, marine safety education activities, mutually promote and improve ocean consciousness and knowledge.

\section{Non-governmental Organizations and Public Welfare Organizations, etc}

Not limited by government and enterprises, to play the role of associations, and to develop mass activities.

\section{CONCLUSION}

The oceans of the world are linked, the development and utilization of which inevitably needs the international cooperation and exchanges. In the era of economic globalization, strengthening the consciousness of sea power, marine economy development, promotion of the exchange of marine culture have become the strategic power embodiment of a country. For China, a country which backs against the Eurasian continent and near the Pacific Ocean, the strengthening of marine cooperation with foreign countries is extremely significant in geopolitics, national security and economic development.

\section{ACKNOWLEDGMENT}

Fund Support: Maritime Cultural Construction of Teaching Resource Library

\section{CORRESPONDING AUTHOR}

Cao Qing, 1035489485@qq.com, +86 15022358128 fax number: +86 02228779661

\section{REFERENCES}

[1] State Council "Twelve Five Year Plan" on the issuance of the national marine economic development [EB/OL].
[ http://www.gov.cn/zwgk/2013-01/17/content_2314162.htm

[2] Zhou zuyi (CPPCC Committee, Party secretary of Tongji University), Must attach great importance to the integration of marine scientific research [N]. Nanfang Daily. 2013-3-11

[3] Premier Li Keqiang speech at the China-Greek maritime cooperation forum.

[EB/OL].http://news.xinhuanet.com/world/2014-06/21/c_1266510 68.htm

[4] Zhou fangyin, Maritime Silk Road reflects China's great power play [N]. People's Daily. 2014-6-27

[5] Bai qinghong, Deepening the management model, Construction seafarers power[N]. China Water Transport News. 2014-6-27

[6] Xie wenxin, Construction in the 21st Century "Marine Silk Road" and the opportunity to play in Guangdong Province [EB/OL]. http://bbs.southcn.com/thread-7840898-1-1.html 